\title{
THE EFFECTS OF ACUTE CARDIAC INFARCTION AND OF HEPARIN THERAPY ON THE LIPOPROTEINS
}

BY

\author{
E. M. M. BESTERMAN \\ From the Institute of Cardiology \\ Received May 27, 1957
}

In a comparison of the lipoprotein patterns found in the sera of ischæmic and control subjects, an increased pre- $\beta$ lipoprotein (Dangerfield and Smith, 1955), was found in 99 per cent of 200 patients with ischæmic heart disease (Besterman, 1957). Further analysis of these findings showed that the pre- $\beta$ lipoprotein was most plentiful in those with acute coronary insufficiency and least in those seen within a few hours of acute cardiac infarction. As many of these patients received anti-coagulant therapy the effects of heparin on the lipoprotein patterns have also been investigated.

The serum lipoproteins were studied by paper electrophoresis as previously described. The proportion of each of the three lipoproteins, $\beta$, pre- $\beta$, and $\alpha$, was determined by planimetry of graphs derived from the paper electrophoretograms. As no strict quantitative accuracy can be expected from paper electrophoresis, the area of each lipoprotein has been expressed as a fraction of the total area of lipoproteins present.

Acute Infarction. The quantity of pre- $\beta$ lipid present in the sera of patients with angina of effort was similar to that found in the sera of patients with established cardiac infarction (Table I).

TABLE I

Pre- $\beta$ Lipoprotein Fraction in different types of Ischemic Disease

\begin{tabular}{l|c|c|c|c|c}
\hline & $\begin{array}{c}\text { Angina of } \\
\text { effort }\end{array}$ & $\begin{array}{c}\text { Acute coronary } \\
\text { insufficiency }\end{array}$ & $\begin{array}{c}\text { Acute cardiac } \\
\text { infarction }\end{array}$ & $\begin{array}{c}\text { Established } \\
\text { cardiac infarction }\end{array}$ & Controls \\
\hline Pre- $\beta$ fraction $\ldots$ & $0.207 \pm 0.012$ & $0.235 \pm 0.017$ & $0 \cdot 1 \pm 0.029$ & $0 \cdot 213 \pm 0 \cdot 009$ & $0.008 \pm 0.01$ \\
\hline Number of patients & 60 & 35 & 15 & 105 & 78 \\
\hline
\end{tabular}

However, patients with a typical history and the electrocardiographic changes of acute coronary insufficiency had a greater amount of pre- $\beta$ lipid, whereas patients seen within 24 hours of acute cardiac infarction had a significantly diminished pre- $\beta$ fraction (Fig. 1). This change has also been observed by Smith (1956). Fifteen cases were studied within a day of the onset of infarction: little or no pre- $\beta$ lipoprotein was present in the sera of seven of these and a reduced pre- $\beta$ fraction was present in the remaining eight. Similarly this fraction was reduced or absent in 19 patients first studied one to three days after infarction (Table II). Subsequent studies on sera from these cases showed the appearance of a marked pre- $\beta$ lipoprotein, attaining maximum proportions two to three weeks after the acute episode. The fraction then diminished over succeeding weeks and eventually remained at the level observed in cases of established infarction. No significant difference in the $\beta$ or $\alpha$ lipoproteins was observed in these patients with acute infarction. Similarly no difference in distribution of $\beta$ and $\alpha$ fractions was found on comparison of the four groups of ischæmic patients shown in Table I. No cases were studied immediately before infarction, 


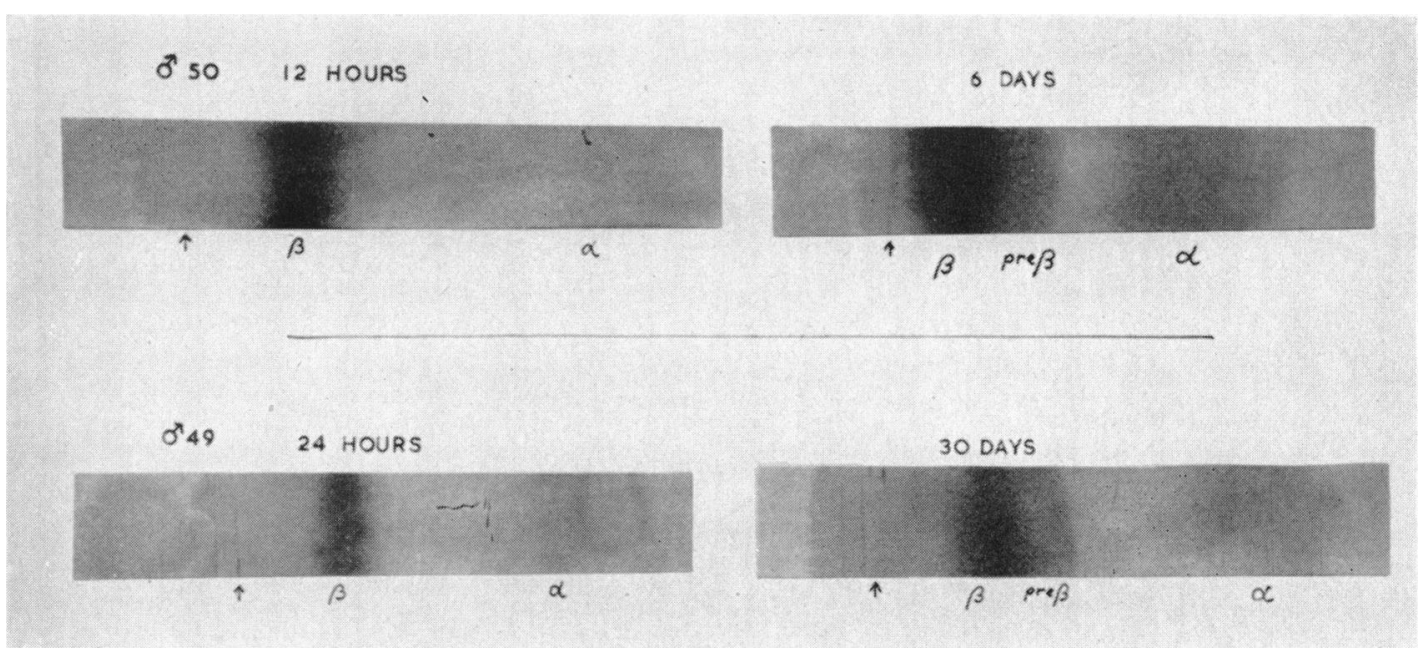

Fig. 1.-Lipoprotein pattern in cardiac infarction; pre- $\beta$ lipid absent at the acute stage, but present subsequently.

TABLE II

Pre- $\beta$ Fraction following Acute Infarction

\begin{tabular}{l|c|c|c|c|c|c}
\hline \begin{tabular}{c} 
Days after infarct \\
\hline Pre- $\beta$ fraction $\ldots$
\end{tabular} & $0 \cdot 1 \pm 0.029$ & $0 \cdot 169 \pm 0.021$ & $0 \cdot 213 \pm 0.018$ & $0 \cdot 225 \pm 0.011$ & $0 \cdot 237 \pm 0.016$ & $0.227 \pm 0.013$ \\
\hline $\begin{array}{c}\text { Number of } \\
\text { patients }\end{array}$ & 15 & 19 & 16 & 10 & 11 & 11 \\
\hline
\end{tabular}

but one patient was seen shortly after each of three acute infarcts and was observed in the intervening periods. Little or no pre- $\beta$ lipoprotein was present at the time of each infarct; whereas after recovery this lipid was present to a significant extent. Thus it appears that the pre- $\beta$ lipoprotein alone shows changes during the course of acute cardiac infarction.

\section{EFFECTS OF HEPARIN}

Since the original observations by Hahn (1943) that heparin reduced serum turbidity, there have been many reports on the effects of this substance on lipoproteins. Ultracentrifuge studies by Graham et al. (1951) showed a redistribution of the Sf groups after heparin: there was a reduction of the larger particles and of the Sf 20-100 fraction with a corresponding increase of the Sf 6-12 groups. Using electrophoresis, Rosenberg (1952) demonstrated increased mobility of both $\beta$ and $\alpha$ lipoproteins after heparin, without changes in the plasma proteins. Spitzer (1952) found that heparin had no effect on the total fat content of serum, but caused a redistribution of the lipids.

The majority of patients treated for coronary insufficiency or recent infarction received anticoagulant therapy. The opportunity was taken for observing the effects of heparin on the lipoprotein patterns in these cases. Heparin $100 \mathrm{mg}$. was injected intravenously, blood samples being obtained before injection and at 20 minutes, at one, and at four hours afterwards. Some patients received subsequent heparin injections and in all, the effects of 122 injections in 89 patients were studied. To ensure comparable results, electrophoresis was carried out simultaneously on the four serum specimens from each case. Electrophoresis of the same sera was repeated two or three times in order to verify the findings. 
Results. Owing to errors of technique no satisfactory interpretation of results was possible following 21 injections in 10 patients. After the remaining 101 heparin injections, reduction or disappearance of the neutral fat occurred in all cases in which it was initially present. In 10 per cent there was no change in lipoprotein pattern following heparin. However, three different changes were seen in the remaining 90 per cent: increased mobility of both $\beta$ and $\alpha$ lipid in 30 per cent, increased migration of the $\beta$ lipid alone in 24 per cent, and disappearance of the pre- $\beta$ fraction without any alteration of mobility of the $\beta$ and $\alpha$ lipoproteins in 36 per cent. Increased mobility of the lipoproteins frequently resulted in poor definition of their boundaries and planimetry was therefore only undertaken on graphs obtained from those electrophoretograms in which the lipoproteins were distinctly delineated.

The neutral fats or triglycerides are particles of larger size than the lipoproteins and fail to migrate on paper electrophoresis. They adhere to the paper at the site of application of the serum and, if present in quantity, form a distinct band at this point. However, many patients with recent cardiac infarction had not eaten for some time before admission to hospital, and in these cases little or no neutral fats were found. When present, the triglycerides were invariably reduced by heparin. This action of heparin is analogous to the reduction of visible lipæmia in post-prandial sera by the drug. An absolute diminution of serum neutral fat content following heparin has been shown by Herzstein et al. (1954) and Nikkila (1954). This clearing action of heparin has been extensively investigated and it is believed that heparin is not the actual clearing agent, but that it is a necessary precursor of the clearing factor (Anfinsen et al., 1952). After heparin injections Grossman (1955) found that hydrolysis of the triglycerides occurred with an increase of serum fatty acids and it appears that the clearing factor is lipoprotein lipase (Korn, 1955). Grossman (1955) considered that this process might be a normal part of the cycle of fat metabolism in man: this view is supported by the demonstration of endogenous clearing factor (Engelberg, 1955).

In nine patients no change in lipoprotein pattern was seen following eleven heparin injections (Fig. 2). There was no apparent technical fault, and the refractory lipoprotein state appeared to be a true finding. It was of interest that six of these subjects were suffering from acute infarcts. Moreover one was subsequently treated for two further acute infarcts and on each occasion proved to be resistant to the antilipæmic action of the drug (M.C., Fig. 2). Heparin sensitivity tests were not performed and clotting times were not estimated as a routine. The three remaining patients who proved refractory to the antilipæmic effects of heparin had had acute infarcts within the previous two weeks.

Increased mobility of both $\beta$ and $\alpha$ lipoproteins occurred following 30 heparin injections in 25 patients (Fig. 3). Satisfactory graphs were obtained from 16 of these electrophoretograms. After heparin the $\beta$ lipoprotein migrated $7 \mathrm{~mm}$. further than before injection, an increase of 11.5 per cent. No distinct pre- $\beta$ lipid could be seen in any of these electrophoretograms following heparin injection. It was not initially apparent whether the pre- $\beta$ failed to accelerate and was consequently concealed by the more mobile $\beta$ fraction, or whether its own mobility had increased to such an extent that it had fused with the $\alpha$ lipoprotein. However, calculations from the graphs suggested that an increase of both $\beta$ and $\alpha$ fractions had occurred following heparin. If this increase can be ascribed to redistribution of the pre- $\beta$ lipid alone, 64 per cent of the pre- $\beta$ fraction was apparently merged with the $\beta$ and 36 per cent with the $\alpha$ lipoprotein. Hypermobility of the $\alpha$ lipoprotein occasionally resulted in its migration beyond the albumin band of the plasma proteins. In such cases a distinct pre-albumin protein was found as described by Herbst et al. (1954). Otherwise the plasma proteins were completely unaffected by heparin.

Increased mobility of the $\beta$ fraction alone occurred following 28 heparin injections in 20 patients. In these cases the $\alpha$ lipid was unaffected. Analysis of 16 graphs from these electrophoretograms showed an 11 per cent increase of $\beta$ migration after heparin. The pre- $\beta$ lipid was no longer detectable and its redistribution following heparin was apparently similar to that found in the previous cases, 67 per cent being added to the $\beta$ and 33 per cent to the $\alpha$ fractions.

Disappearance of the pre- $\beta$ lipid occurred in the absence of any increased migration of either 


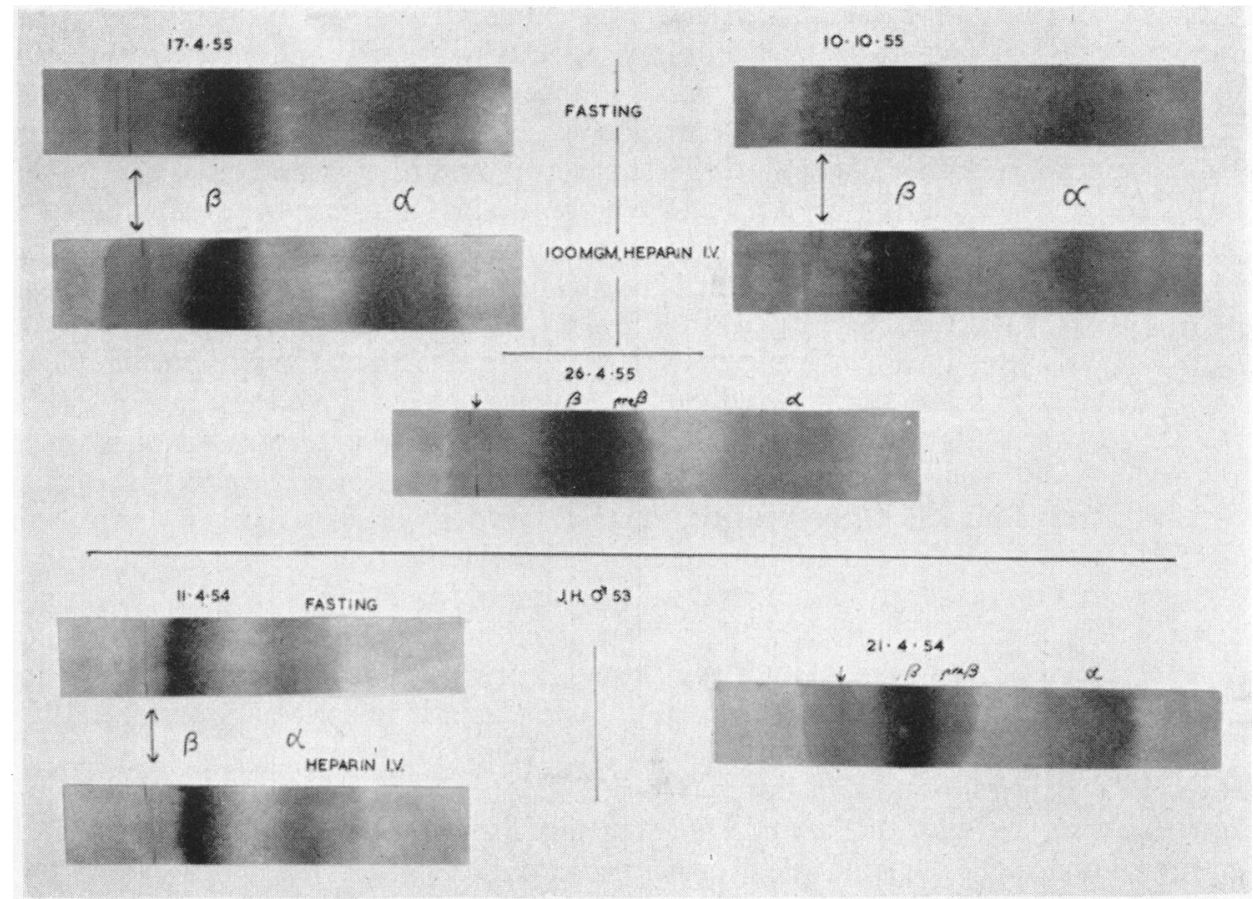

FIg. 2.-Absent pre- $\beta$ lipid in acute cardiac infarction with no change in lipoproteins following intravenous heparin. Appearance of pre- $\beta$ subsequently.

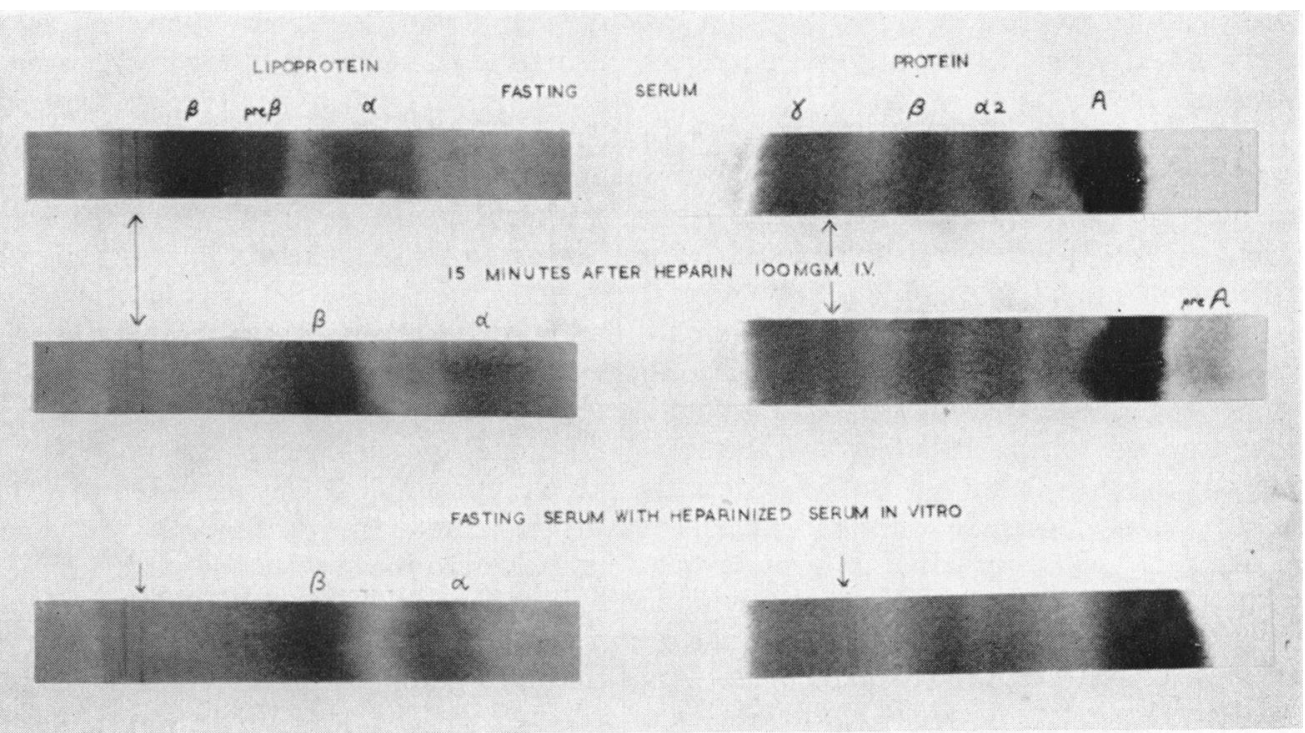

FIG. 3.-Increased mobility of $\beta$ and $\alpha$ lipoproteins following both intravenous heparin and addition of heparinized serum in vitro. 
$\beta$ or $\alpha$ lipoproteins, after 31 heparin injections in 30 patients (Fig. 4). Graphs derived from 29 of these electrophoretograms were studied. This was of particular interest and has not been reported previously. The apparent redistribution of the pre- $\beta$ lipid was surprisingly similar to that found in the two previous groups of cases. Of the increase in $\beta$ and $\alpha$ fractions, 70 per cent occurred in the former and 30 per cent in the latter. No change occurred in the proteins of the sera after heparin.

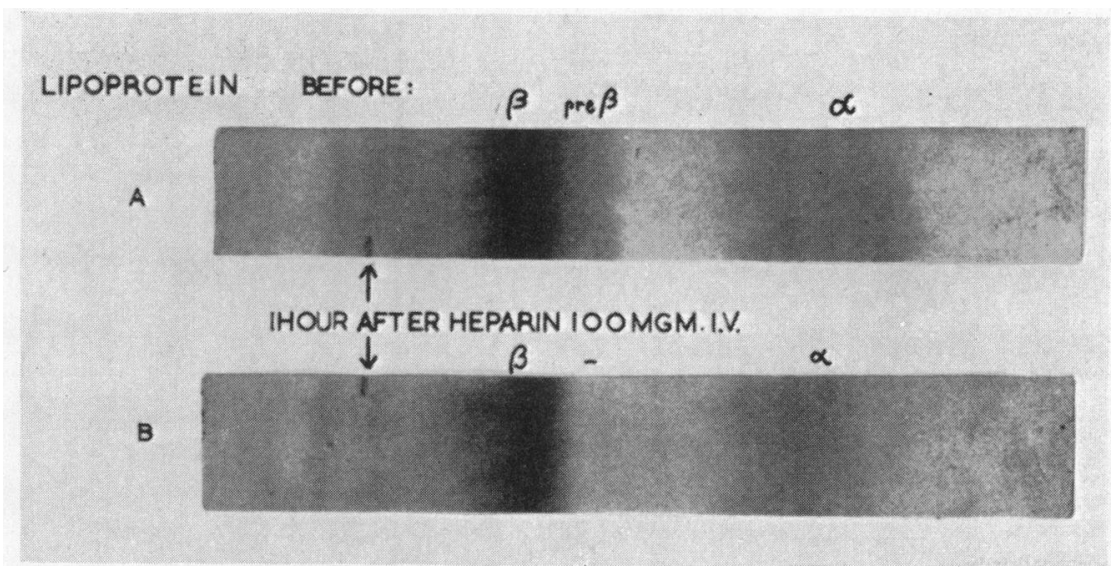

FIG. 4.-Disappearance of pre- $\beta$ lipid following heparin, without alteration in mobility of $\beta$ and $\alpha$ lipoproteins.

Thus it appears that of all three lipoproteins the pre- $\beta$ is most consistently altered following systemic heparin. There was no obvious clinical difference between the patients whose sera showed the varying responses to intravenous heparin. The results of the heparin were always apparent within two minutes of injection and persisted for 18 to 24 hours.

In Vitro Heparin.-The effects of heparin in vitro were then investigated. Anderson (1950) showed that serum obtained from a heparinized subject would clear the turbidity of another serum in vitro. The action of heparinized serum was studied in 14 cases: in all of these increased migration of the $\beta$ lipoprotein occurred, a 12 per cent increase on comparison with the control serum, and in some the $\alpha$ was also affected (Fig. 3). The pre- $\beta$ lipoprotein present previously could no longer be discerned after addition of heparinized serum. 80 per cent of the pre- $\beta$ lipid appeared to become merged with the $\beta$ and 20 per cent with the $\alpha$ lipoproteins.

Heparin alone in vitro is reputedly without effect. Nevertheless it was decided to study this problem. 100 units of heparin were added to $1 \mathrm{ml}$. of serum and left at room temperature for one hour. This provided a concentration of heparin 50 times greater than that obtained in vivo with the usual therapeutic dosage. A significant lipoprotein redistribution occurred in 12 out of 14 sera to which heparin was added (Fig. 6). An 18 per cent increase of $\beta$ lipid mobility was observed following heparin, the $\alpha$ being little altered. The redistribution of the pre- $\beta$ fraction was again similar to that found after heparin in vivo, 71 per cent being added to the $\beta$ and 29 per cent to the $\alpha$ fractions.

Thus it appears that both heparinized serum and high concentrations of heparin in vitro can alter the lipoprotein in a manner similar to that found with systemic heparin. In vitro studies with heparin never reproduced the in vivo effect of a reduced pre- $\beta$ lipid without hypermobility of the $\beta$ and $\alpha$ fractions.

Heparin in Acute Infarction. A similar reduction of pre- $\beta$ lipid was thus found both in some cases of acute infarction and in one-third of the cases following intravenous heparin-those without altered mobility of $\beta$ and $\alpha$ lipids. The effects of heparin were therefore studied in 17 patients treated within 24 hours of infarction. The sera from six of these showed no change after systemic 


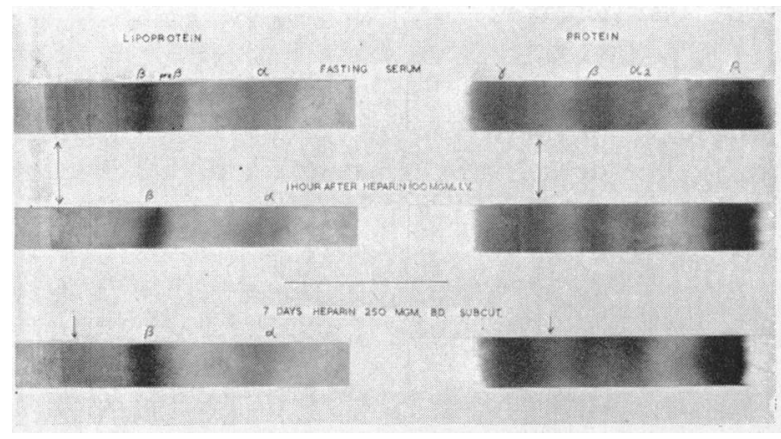

FiG. 5--Persistent change in lipoprotein pattern produced by daily subcutaneous heparin therapy.

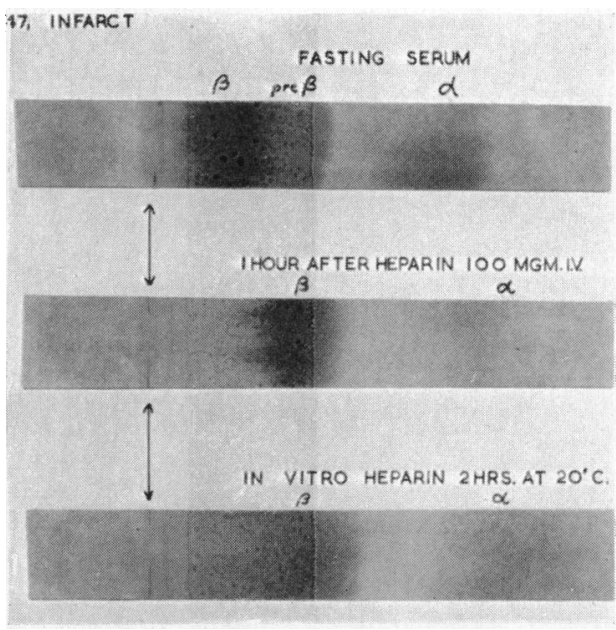

FIG. 6.-Similar effect of intravenous heparin and of in vitro heparin on lipoprotein mobility.

heparin (Fig. 2). One (upper part, Fig. 2) was treated for three acute infarcts during 18 months and was refractory to heparin on each occasion. Thus there were eight episodes of infarction in which heparin had no effect on the lipid pattern: in none of these was any obvious pre- $\beta$ lipoprotein present at the acute stage, but it subsequently appeared. A pre- $\beta$ lipid was present in the sera of the remaining 11 patients. After heparin, the pre- $\beta$ fraction alone was affected in five, and increased mobility of the $\beta$ and $\alpha$ fractions occurred in six cases.

It has been suggested that heparin or a heparin-like substance is normally secreted by the body. Studying peptone shock in dogs, Havel (1954) and Worley (1955) have demonstrated prolonged clotting times and release of clearing factor. These effects have been ascribed to secretion of endogenous heparin. The mast cells are considered to be a possible source of endogenous heparin and Cairns (1954) has noted an inverse correlation between tissue mast-cell content and susceptibility of the subject to alimentary lipæmia. In human hearts lower mast-cell counts were found in atheromatous than in healthy subjects.

The apparent heparin-resistant state of some patients with acute infarction might be ascribed to a pre-existing heparin effect following endogenous secretion in response to the stimulus of infarction. This is suggested by the absence of a pre- $\beta$ lipid in these refractory cases, whereas all those showing a response to heparin had a pre- $\beta$ lipoprotein. Furthermore five of the resistant cases had extensive infarcts and three of them were also suffering from shock. The similarity of lipoprotein pattern in some cases of acute infarction to that found after systemic heparin suggested that prolonged heparin therapy might be of value.

Prolonged Heparin Therapy. Three patients have been treated with daily heparin for three weeks and one for over a year, with adequate lipoprotein studies. In two, with recent infarction, heparin was substituted for dindevan in view of continued ischæmic pain despite complete rest. The third was admitted within two hours of a first infarct. The fourth suffered from hypercholesterolæmia, severe xanthoma tuberosum and tendinosum, as well as ischæmic heart disease; he developed an infarct while under observation in hospital, and heparin was then started. All four received anticoagulant doses, $250 \mathrm{mg}$. subcutaneously twice daily for three weeks. The fourth patient, with xanthomatosis, thereafter continued single daily injections of $250 \mathrm{mg}$. of heparin, and this reduced dosage was adequate for an anti-lipæmic action of 24 hours' duration.

No untoward effects occurred. In two cases local pain made it necessary to add $1 \mathrm{ml} .2$ per cent procaine to each injection of heparin $(250 \mathrm{mg}$. $/ 1 \mathrm{ml}$.). Subcutaneous administration is less 
likely to cause hæmatomata than intramuscular injections. However subsequent experience with further patients has shown that subcutaneous injections in women frequently cause local hæmorrhage.

The lipoprotein pattern was consistently altered in all four cases throughout the period of treatment (Fig. 5). Increased mobility of both $\beta$ and $\alpha$ lipoproteins persisted, and no pre- $\beta$ fraction was visible: 24 hours after stopping heparin the pre- $\beta$ band was again obvious on electrophoresis. A further lipoprotein effect was observed in these patients on prolonged therapy that was not seen after single injections of heparin: an increase of the $\alpha$ and diminution of the $\beta$ fractions occurred and persisted for up to two weeks after stopping treatment. A similar change appeared in the serum of the patient with xanthomatosis, and has persisted subsequently during his continued heparin therapy (Fig. 7). This apparent shift of lipoprotein from $\beta$ to $\alpha$ following heparin has been observed by Bolinger (1953), Nikkila and Grasbeck (1954) and others, but denied by Herbst et al. (1955). It appears from the present study that this change in distribution does not occur unless prolonged heparin therapy is administered.

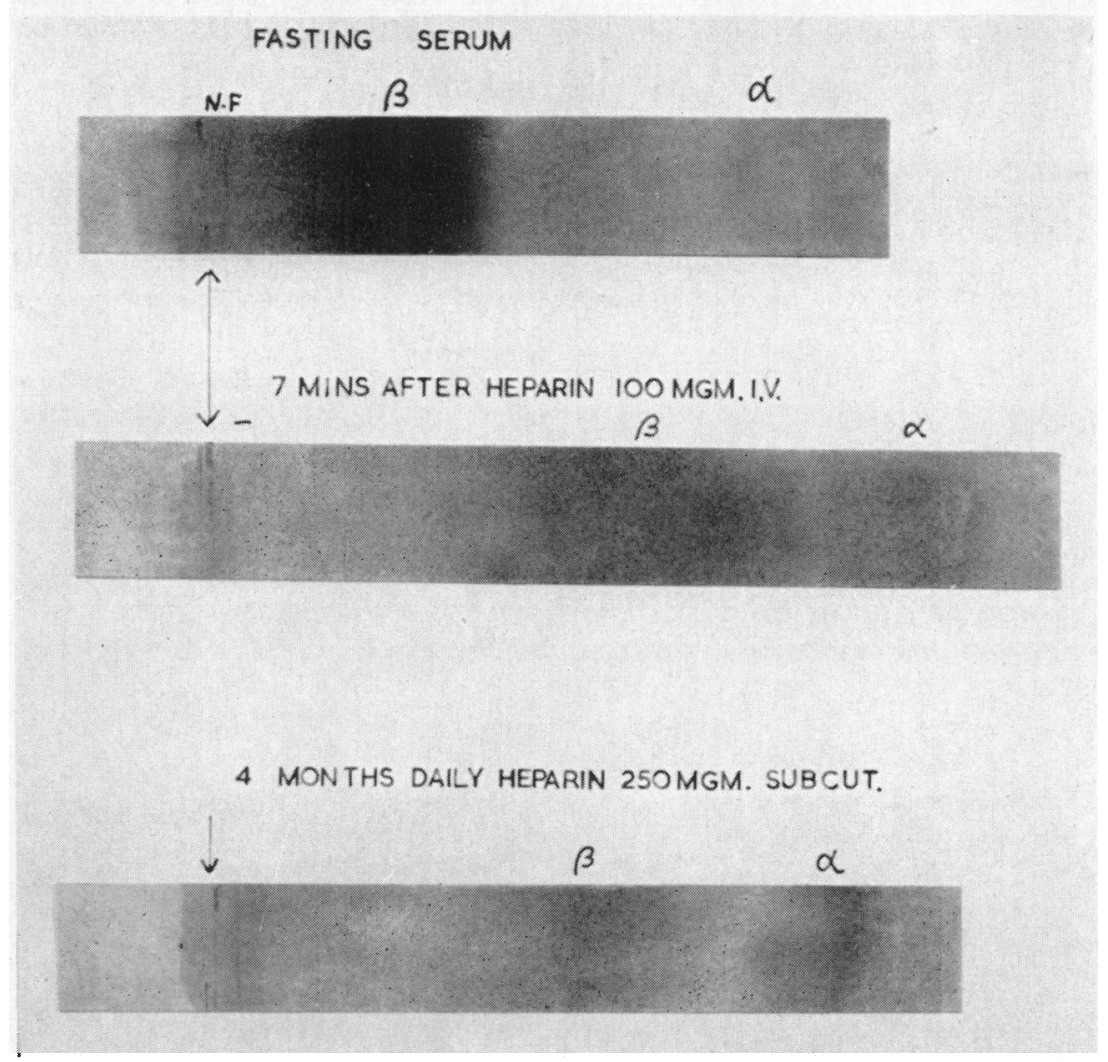

FIG. 7.-Diminution of $\beta$ and increase of $\alpha$ lipoproteins after four months' daily heparin in a case of xanthomatosis.

Cholesterol. The serum cholesterol was reduced from $450 \mathrm{mg}$. per $100 \mathrm{ml}$. to $210 \mathrm{mg}$. per $100 \mathrm{ml}$. during heparin treatment in the patient with xanthomatosis alone, and furthermore the xanthomata showed a progressive reduction in size. Serum cholesterol was estimated by the Myers and Wardell technique. No significant change occurred in the serum cholesterol following single injections of heparin. The initial cholesterol levels were within normal limits in the three patients on prolonged heparin therapy and no change occurred during treatment. 
Protamine. It has been reported that protamine antagonizes the effects of heparin on the lipoproteins (Brown, 1952; and Gruner, 1953). In the present study it was found that intravenous protamine sulphate modified the heparin changes but never completely abolished them. This is in accord with the results of Nikkila (1953). Protamine added in vitro had no antagonistic effect on the antilipæmic action of heparin.

Oleic Acid. The increased mobility of the lipoproteins following heparin has been ascribed to release of fatty acids following lipolysis by the clearing factor. The effects of oleic acid added to serum in vitro have been investigated by Gordon (1955). His findings have been confirmed in the present study. Within one minute of adding oleic acid, hypermobility of both $\beta$ and $\alpha$ lipoproteins was apparent (Fig. 8), greater in degree than that seen following heparin.

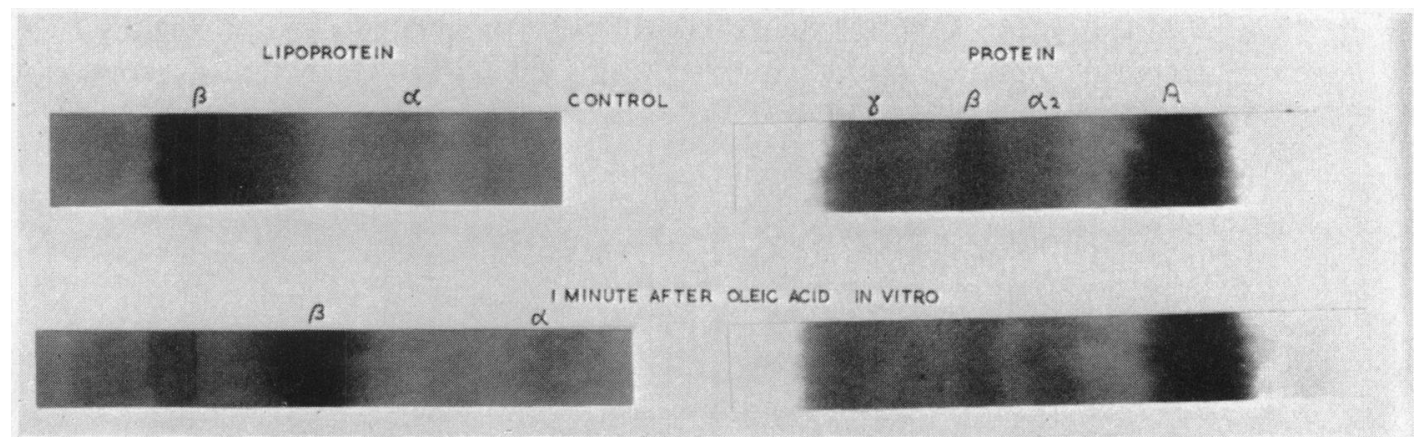

FIG. 8.-Increased mobility of lipoproteins following addition of oleic acid in vitro.

Incubation. Initial in vitro studies with heparin and protamine were carried out after incubation at $37^{\circ} \mathrm{C}$. However it was found that the control serum also showed an altered lipoprotein distribution. Therefore subsequent in vitro heparin studies were conducted at room temperature, and the effects of incubation per se were investigated. Thirty sera were incubated at $37^{\circ}$ for 2 to 24 hours. Eighteen of these showed increased migration of the $\beta$ lipoprotein when compared with the same serum kept at room temperature (Fig. 9). This effect was comparable to that seen after heparin. It occurred within two hours in some cases, and remains unexplained. It is possible that hydrolysis or decomposition of the lipoproteins may have occurred.

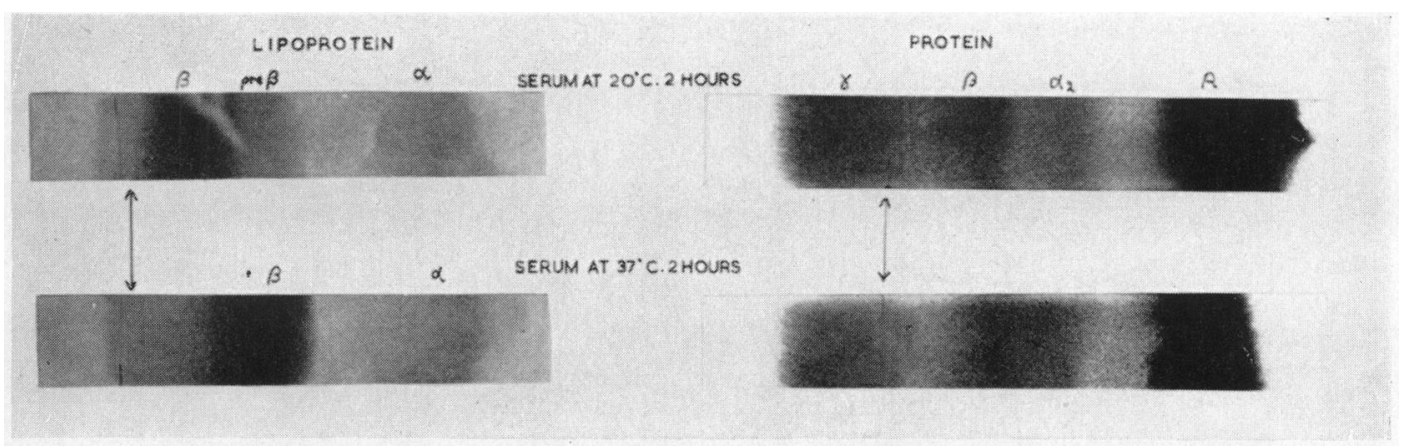

FIG. 9.-Increased mobility of $\beta$ lipoprotein following incubation of serum at $37^{\circ} \mathrm{C}$. for two hours.

\section{Discussion}

Following systemic or in vitro heparin, various changes in lipoprotein pattern have been observed. The most consistent effect has been the disappearance of the pre- $\beta$ lipoprotein which is apparently redistributed between the $\beta$ and $\alpha$ lipoproteins. The action of heparin that results in 
increased lipoprotein mobility and clearing of neutral fats has been ascribed to fatty acid release following hydrolysis of the triglycerides. Although it is probable that the pre- $\beta$ fraction is affected by a similar mechanism, one-third of the cases showed an effect on this lipid alone unaccompanied by hypermobility of the other lipoproteins. It is possible that some other heparin action is responsible for this effect. The lipoprotein pattern produced by this selective effect of heparin closely resembled that found in the sera of some cases of acute infarction that had proved resistant to the antilipæmic action of heparin. It would be rash to attribute too great a significance to this resemblance of electrophoretic patterns, yet this refractory state might possibly be due to the previous secretion of an endogenous heparin-like substance. This resistance to heparin might also be explained by the release of an anti-heparin substance, or else by the lack of an intermediate compound necessary for the production of clearing factor following exogenous heparin. From earlier studies it is known that significant amounts of pre- $\beta$ lipoprotein occur in the sera of patients with ischæmic heart disease. This lipid may be transiently cleared in some cases at the time of infarction, whereas it remains in others and also in those with acute coronary insufficiency. In the latter cases systemic heparin produces a marked effect on the lipoprotein pattern. It might be postulated that such patients have insufficient endogenous heparin or else that the release of this substance only occurs after massive cardiac infarction and necrosis of considerable amounts of cardiac muscle. Havel (1954) and Worley (1955) have made the interesting suggestion that an endogenous heparin may play a normal role in fat transport: reduction of this substance might explain the presence of excessive amounts of pre- $\beta$ lipid in ischæmic subjects.

These findings suggest that patients with cardiac infarction may benefit from prolonged heparin therapy by virtue of the drug's anticoagulant action initially and its anti-lipæmic effect in smaller dosage thereafter. Unfortunately prolonged heparin therapy is not practicable for any large number of patients. Attempts are being made to find related compounds with the antilipæmic properties of heparin, yet free from anticoagulant activity (Constantinides et al., 1954; and Besterman, 1957).

\section{SUMMARY}

The lipoprotein patterns were compared in patients with various types of ischæmic heart disease. The distribution of the pre- $\beta$ lipid alone was found to differ, being greater in cases of acute coronary insufficiency and abnormally diminished in those with acute cardiac infarction. Significant quantities of pre- $\beta$ lipid subsequently appeared in these cases during recovery.

The effects of heparin on the lipoproteins were also studied: 10 per cent of the cases showed no change in lipid pattern, 54 per cent hypermobility of the lipoproteins, and 36 per cent reduction of the pre- $\beta$ lipid without increased mobility of the $\beta$ and $\alpha$ fractions. Increased migration of the lipoproteins also resulted from in vitro addition of heparinized serum, heparin, or oleic acid, or from incubation at $37^{\circ} \mathrm{C}$. Prolonged heparin therapy was carried out in four patients, including one with xanthomatosis: redistribution of lipid between the $\beta$ and $\alpha$ fractions occurred in these patients alone.

Acute cardiac infarction had occurred in 8 of the 11 heparin resistant cases and no pre- $\beta$ lipid was present in their sera. This lipoprotein pattern resembled the selective heparin effect on this lipid seen after 36 per cent of heparin injections. It is possible that such patients may be refractory to exogenous heparin owing to previous endogenous heparin release.

Dr. Paul Wood, Director of the Institute of Cardiology, has unceasingly encouraged and advised me in this study and I am most grateful to him and to the other physicians of the National Heart Hospital for their kind co-operation. I am also indebted to the R.M.O and Registrars of the National Heart Hospital for their help. Dr. W. Dangerfield has, as always, given me invaluable criticism and advice. Miss B. Hall has provided the most patient technical assistance throughout this study. The heparin was supplied through the courtesy of Dr. E. V. B. Morton of Boots.

\section{REFERENCES}

Anderson, N. G., and Fawcett, B. (1950). Proc. Soc. exp. Biol., 74, 768.

Anfinsen, C. B., Boyle, E., and Brown, R. K. (1952). Science, 115, 583.

Besterman, E. M. M., and Evans, J. (1957). Brit. med. J., 1, 310. 
Besterman, E. M. M. (1957). Brit. Heart J. 19, 503

Bolinger, R. E., Grady, H. J., and Slinker, B. J. (1953). Amer. J. med. Sci., 227, 193.

Brown, W. D. (1952). Quart. J. exp. Phys., 37, 215.

Cairns, A. (1954). Science, 120, 31.

Constantinides, P., Cairns, A., and Werner, A. (1954). Arch. Int. Pharmacodyn., 99, 334.

Dangerfield, W. G., and Smith, E. B. (1955). J. clin. Path., 8, 132.

Engelberg, H. (1955). Amer. J. Phys., 181, 309.

Gordon, R. C. (1955). J. clin. Invest., 34, 477.

Graham, D. M., Lyon, T. P., Gofman, J. W., Jones, H. B., Yankley, A., Simonton, J., and White, S. (1951). Circulation, 4, 666.

Grossman, M. I., Moeller, H. C., and Palm, L. (1955). Proc. Soc. exp. Biol., 90, 106.

Grüner, A., Hilden, K., and Hilden, T. (1953). Scand. J. clin. Lab. Invest., 5, 241.

Hahn, P. F. (1943). Science, 98, 19.

Havel, R. J., and Boyle, E. (1954). Proc. Soc. exp. Biol., 85, 468.

Herbst, F. S. M., and Hurley, N. A. (1954). Jour. clin. Invest., 33, 907.

$\longrightarrow$, Lever, W., Lyons, M. E., and Hurley, N. A. (1955). J. clin. Invest., 34, 581.

Herzstein, J., Chun-I Wang, and Adlersberg, D. (1954). Ann. intern Med., 40, 290.

Korn, E. D. (1955). J. biol. Chem., 215, 1.

Nikkila, E. (1953). Scand. J. clin. Lab. Invest., 5, suppl. 8.

- and Grasbeck, R. (1954). Acta. med. scand., 150, 39.

Rosenberg, I. N. (1952). Proc. Soc. exp. Biol., 80, 751.

Smith, E. B. (1956). Ph.D. thesis, London.

Spitzer, J. J. (1952). Amer. J. Phys., 171, 492.

Worley, L. M., and Lequire, V. S. (1955). Proc. Soc. exp. Biol., 89, 181. 